\title{
Perinatal Exposure to Bisphenol A or Diethylstilbestrol Increases the Susceptibility to Develop Mammary Gland Lesions After Estrogen Replacement Therapy in Middle-Aged Rats
}

\author{
Ayelen L. Gomez ${ }^{1}$ Melisa B. Delconte ${ }^{1}$ - Gabriela A. Altamirano ${ }^{1} \cdot$ Lucia Vigezzi $^{1}$ \\ Veronica L. Bosquiazzo ${ }^{1}$ • Luís F. Barbisan ${ }^{2}$ Jorge G. Ramos ${ }^{1} \cdot$ Enrique H. Luque $^{1}$ • \\ Mónica Muñoz-de-Toro ${ }^{1} \cdot$ Laura Kass $^{1}$
}

Received: 1 September 2016 / Accepted: 23 December 2016/Published online: 11 January 2017

(C) Springer Science+Business Media New York 2017

\begin{abstract}
The development of the mammary gland is a hormone-regulated event. Several factors can dysregulate its growth and make the gland more susceptible to cellular transformation. Among these factors, perinatal exposure to xenoestrogens and hormone replacement therapy has been associated with increased risk of developing breast cancer. Here, we assessed the effects induced by estrogen replacement therapy (ERT) in ovariectomized (OVX) middle-aged rats and whether perinatal exposure to diethylstilbestrol (DES) or bisphenol A (BPA) modified these effects in the mammary gland. Pregnant rats were orally exposed to vehicle, $5 \mu \mathrm{g}$ $\mathrm{DES} / \mathrm{kg} / \mathrm{day}$, or 0.5 or $50 \mu \mathrm{g} \mathrm{BPA} / \mathrm{kg} /$ day from gestational day 9 until weaning. Then, 12 -month-old offspring were OVX and treated with $17 \beta$-estradiol for 3 months. Morphological changes and the percentage of epithelial cells that proliferated or expressed estrogen receptor alpha (ESR1) and progesterone receptor (PR) were analyzed in mammary gland samples of 15-month-old animals. ERT induced lobuloalveolar hyperplasia and ductal cysts in the mammary gland of middle-aged rats, associated with a higher proliferation index of epithelial cells. Perinatal exposure to DES followed by ERT increased the number of cysts and induced the formation of fibroadenoma and ductal carcinoma in situ, without modifying the expression of ESR1 or PR. Also, after
\end{abstract}

Laura Kass

lkass@fbcb.unl.edu.ar

1 Instituto de Salud y Ambiente del Litoral (ISAL), Universidad Nacional del Litoral (UNL)-Consejo Nacional de Investigaciones Científicas y Técnicas (CONICET), Facultad de Bioquímica y Ciencias Biológicas, UNL, Paraje El Pozo, Casilla de Correo 242, 3000 Santa Fe, Argentina

2 Departamento de Morfologia, Instituto de Biociências, Universidade Estadual Paulista (UNESP), Botucatu, SP, Brazil
3 months of ERT, BPA-exposed rats had a higher incidence of ductal hyperplasia and atypical lobular hyperplasia than animals under ERT alone. In conclusion, perinatal exposure to xenoestrogens increases the susceptibility of the mammary gland to develop cysts and hyperplastic lesions when confronted with ERT later in life.

Keywords Mammary gland · Bisphenol A ·

Diethylstilbestrol · Estrogen replacement therapy $\cdot$ Endocrine disruptor

\section{Introduction}

The intrauterine hormonal milieu may predispose an individual to a disease later in life [1,2]. Currently, concern about the effects of prenatal/perinatal estrogen exposure is focused on exposure to environmental estrogens, which may enhance the risk of breast cancer [2-7]. One of the most widespread endocrine disrupting chemicals (EDCs) is bisphenol A (BPA) [8-10]. Several studies have identified adverse effects of BPA at levels equal to or below the acceptable human intake dose (RfD $50 \mu \mathrm{g}$ BPA $/ \mathrm{kg} /$ day) established by the US Environmental Protection Agency [11]. Moreover, prenatal exposure to low doses of BPA alters the mammary gland development of female primates and rodents and promotes the development of intraductal hyperplasia and precancerous/cancerous mammary lesions in adult rodents [12-18]. Seachrist et al. [2] concluded that "there is substantial evidence from rodent studies indicating that early-life BPA exposures below the RfD lead to increased susceptibility to mammary and prostate cancer." However, Delclos et al. [19] found significant effects on the mammary glands only with the highest BPA dose tested $(300,000 \mu \mathrm{g} / \mathrm{kg} /$ day $)$. Another EDC 
to which humans have been exposed is diethylstilbestrol (DES) [20]. The use of DES to prevent miscarriages has resulted in transplacental in utero exposure of numerous individuals to this potent synthetic estrogen [21]. Women prenatally exposed to DES are predisposed to a wide array of reproductive abnormalities [21] and higher risk for breast cancer [22]. Moreover, neonatal treatment with high doses of DES results in precocious lactogenesis in adult nulliparous female mice [23].

Hormone replacement therapy in postmenopausal women is used to alleviate menopausal symptoms [24]. However, the amount of lifetime exposure of the mammary gland to ovarian hormones has been proposed to be a major risk factor for breast cancer development [25]. Although few experimental studies have analyzed the mitogenic effects of estrogen in the postmenopausal breast, it has been reported that in late postmenopausal mice, estrogen causes a pronounced enlargement of duct ends and higher proliferation index compared with the response in early postmenopausal mice [26, 27]. The association between hormone replacement therapy and increased risk of breast cancer is strongly supported by epidemiological studies [28]. A combined estrogen and progesterone replacement therapy (EPRT) seems to have a stronger association with breast cancer risk than an estrogen-only replacement therapy (ERT) [27, 29]. Following publication of those results, the use of EPRT declined rapidly, accompanied by reductions in breast cancer incidence [30]. However, EPRT is still an important therapeutic modality for women with menopausal symptoms and should be considered by physicians for their patients on an individual basis [31]. In this regard, for women who have had a hysterectomy and require treatment, ERT is the most appropriate in terms of minimizing risk [30]. Therefore, any factor such as BPA or DES perinatal exposure that could increase the risk of developing breast cancer associated with ERT is worthy of study.

Experiments have demonstrated that systemic estrogen is sufficient to increase tissue stromalization, cellular density, and angiogenesis [32], and that remodeling, and hence stiffening, of the existing stromal collagen microarchitecture promotes high mammographic density within the breast [33]. The mammary gland stroma of in utero BPA $(25 \mu \mathrm{g} / \mathrm{kg} /$ day $)$-treated animals also exhibits morphological changes in the extracellular matrix: a dense stroma layer is formed around mammary epithelial structures, and a desmoplastic response is observed in the adipose tissue [13]. Taking into account that BPA, DES, or estrogens modify mammary gland morphology, we postulate that prenatal exposure to environmental levels of xenoestrogens may increase the risk of developing mammary gland lesions in postmenopausal individuals receiving ERT. Therefore, our aims were to evaluate the effects induced by ERT and discover whether the perinatal (gestation and lactation) exposure to BPA or DES modified these effects in the mammary gland of middle-aged rats. The mammary gland morphology, epithelial proliferation, estrogen receptor alpha (ESR1), and progesterone receptor (PR) expression were analyzed.

\section{Materials and Methods}

\section{Animals}

All the experimental protocols were approved by the Ethical Committee of the Facultad de Bioquímica y Ciencias Biológicas (FBCB), Universidad Nacional del Litoral (UNL), Santa Fe, Argentina. Sexually mature female rats (90 days old) of a Wistar-derived strain bred at the Department of Human Physiology (FBCB, UNL) were used [34]. Animals were maintained in a controlled environment $\left(22 \pm 2{ }^{\circ} \mathrm{C} ; 14 \mathrm{~h}\right.$ of light) and had free access to pellet laboratory chow (16-014007 Rat-Mouse diet, Nutrición Animal, Santa Fe, Argentina). For more information regarding the food composition, see Andreoli et al. [35] and Altamirano et al. [36]. To minimize exposure to other EDCs, rats were housed in stainless steel cages with sterile pine wood shavings as bedding, and glass bottles with rubber stoppers were used to supply drinking water and oral treatments [36-39].

\section{Experimental Procedures}

The rationale for DES and BPA doses has been explained previously [37]. Briefly, females in proestrus were caged overnight with males of proven fertility and the day that sperm was found in the vagina was designated day 1 of gestation (GD1). On GD9, pregnant rats (F0) were weighed and randomly divided into four groups (10 dams/group): (a) control $(0.002 \%$ ethanol), (b) DES (5 $\mu \mathrm{g} \mathrm{DES} / \mathrm{kg} /$ day), (c) BPA0.5 (0.5 $\mu \mathrm{g}$ $\mathrm{BPA} / \mathrm{kg} /$ day), and (d) BPA50 (50 $\mu \mathrm{g} \mathrm{BPA} / \mathrm{kg} /$ day). All treatments were administered in the drinking water of F0 dams from GD9 to weaning (Fig. 1). Cage bottles were rinsed and refilled twice a week with freshly prepared solutions. DES (Sigma-Aldrich, Buenos Aires, Argentina) and BPA solutions (99\% purity, Sigma-Aldrich) were prepared according to Kass et al. [37]. Individual body weight and water consumption of F0 dams were recorded twice a week throughout the treatment, and the doses were calculated on the basis of their average body weight and water consumption during pregnancy and lactation, and the results have already been published [34, 37-39].

After parturition, litters of eight pups (four males and four females) were left with lactating mothers until weaning on postnatal day (PND) 21. At weaning, the female offspring were kept under standard laboratory animal husbandry conditions. Only one female per litter was included to evaluate whether perinatal exposure to DES or BPA modified the response to a long-lasting treatment with $17 \beta$-estradiol (E). On 


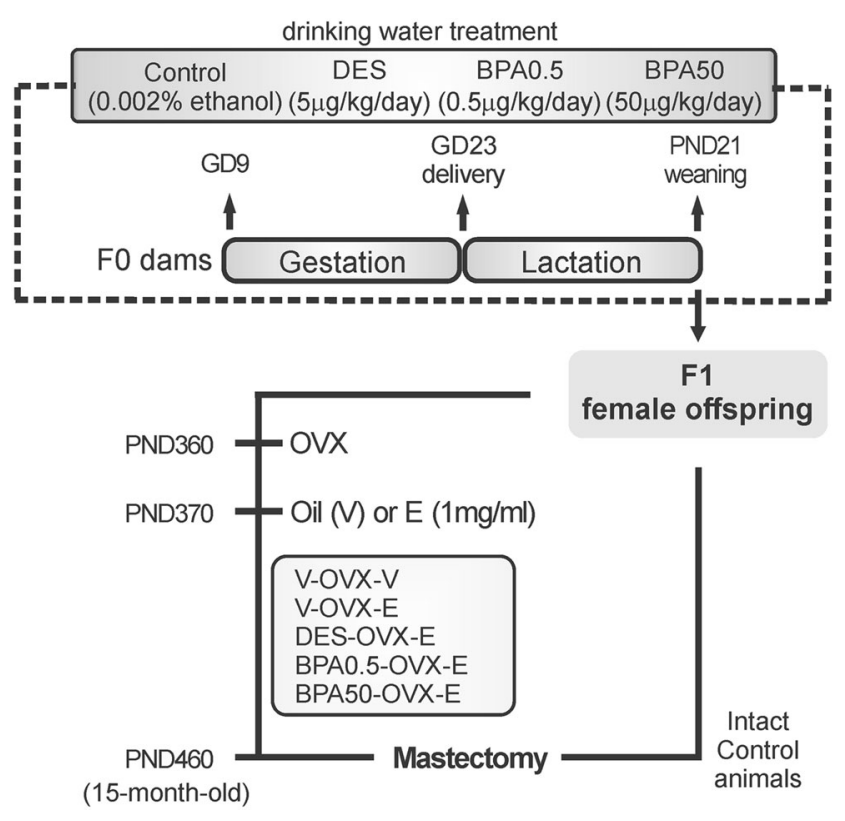

Fig. 1 Schematic representation of the experimental protocol used to study the effects of perinatal bisphenol A (BPA) and diethylstilbestrol (DES) exposure on the mammary gland of female F1 offspring under estrogenic therapy. $G D$ gestational day, $E$ estradiol, $P N D$ postnatal day, $O V X$ ovariectomy, $V$ vehicle (sesame oil)

PND360, the animals were ovariectomized (OVX) to avoid endogenous $\mathrm{E}$ variability. To confirm that the animals were OVX, vaginal smears were obtained every day for a period of 2 weeks; all OVX animals presented vaginal smears characteristic of diestrus. One set of control animals was treated with vehicle (sesame oil, V-OVX-V), and another set of control animals and all DES- and BPA-exposed rats were treated with ERT ( $n=10$ rats/group) for 90 days (Fig. 1) [34, 38, 39]. Rats were implanted (sc) with silastic capsules (outer diameter: $3.18 \mathrm{~mm}$, inner diameter: $1.57 \mathrm{~mm}$, length: $30 \mathrm{~mm}$; Specialty Manufacturing, Midland, MI, USA) filled with $1 \mathrm{mg} \mathrm{E} / \mathrm{ml}$ dissolved in sesame oil. To ensure exposure to constant $\mathrm{E}$ levels, the implants were changed every 30 days, and the animals were sacrificed at 15 months of age (PND460). The treatment with the $\mathrm{E}$ implants produced constant blood levels of $\mathrm{E}$ equivalent to those circulating during the rat estrous cycle [34, 39]. Also, a group of 15-month-old non-OVX (intact) control animals were sacrificed in estrus.

\section{Tissue Sample Collection}

Two hours before sacrifice, 15-month-old rats were injected (ip) with bromodeoxyuridine (BrdU; $6 \mathrm{mg} / 100 \mathrm{~g}$ bw; SigmaAldrich) to determine the proliferative index in the mammary gland [40]. At necropsy, one abdominal-inguinal mammary gland chain was randomly chosen to be processed for whole mount, and the contralateral gland to be fixed in $10 \%(v / v)$ buffered formalin for $24 \mathrm{~h}$ at room temperature and embedded in paraffin [13]. To localize microscopic lesions, the whole mounts were observed under a Zeiss stereomicroscope (Carl Zeiss Microscopy GmbH, Göttingen, Germany), and microscopic or macroscopic lesions were removed and embedded in paraffin for histological analysis [13].

\section{Histology}

Mammary gland samples embedded in paraffin were cut into 5 - $\mu \mathrm{m}$ sections, mounted on slides coated with 3-aminopropyl triethoxysilane (Sigma-Aldrich), and stained with hematoxylin and eosin (H\&E) for light microscopy (Olympus BH2, Tokyo, Japan). The histopathological analysis of the mammary gland was performed by a trained pathologist blinded to the experimental group. Mammary gland slides were subjectively classified as atrophic, hyperplastic, or neither [41]. Hyperplasia, atypia, cystic lesions, and the presence of intraluminal protein or intraepithelial fat globules mimicking secretory activity were recorded. Histological changes were independently graded as none, mild, moderate, or severe, and incidence of these lesions was estimated in each group. Ducts were the only structure where cysts were observed; therefore, to obtain the percentage of cysts present in the mammary gland, all the ducts per section, in two different sections that were at least $30 \mu \mathrm{m}$ apart from each other, were evaluated. The percentage of hyperplastic ducts (with three or more layers of epithelial cells) was quantified by examining H\&Estained sections, as previously described [13]. To obtain the proportion of hyperplastic ducts, we evaluated three sections per mammary gland that were at least $30 \mu \mathrm{m}$ apart from each other, and then analyzed 50 ducts per section. Lobules with atypical hyperplasia were defined when one or more alveoli within a hyperplastic lobule were affected [41]. Alveoli with focal, irregular proliferation of epithelial cells that formed papillae, arches, or nests extending into lumen were quantified. The ratio between lobules with atypical hyperplasia and total lobules per section was analyzed. At least 50 lobules per section and three sections per mammary gland that were $30 \mu \mathrm{m}$ apart from each other were evaluated.

\section{Immunohistochemistry}

Sections from two different depths were used to evaluate the proliferation index (BrdU-positive cells) and the expression of PR and ESR1. Immunoperoxidase staining was performed as previously described [42]. Sections were incubated overnight at $4{ }^{\circ} \mathrm{C}$ with primary antibodies against $\mathrm{BrdU}$ (clone $85-2 \mathrm{C} 8$, Novocastra Laboratories Ltd., Newcastle upon Tyne, UK), PR (PR A/B isoforms, Dako Corp., Carpinteria, CA, USA), and ESR1 (clone 6-F11, Novocastra Laboratories Ltd.). Antirabbit or anti-mouse secondary antibodies (biotinconjugated) (Laboratorio de Endocrinología y Tumores Hormonodependientes, UNL) were used, and reactions were developed using an avidin-biotin peroxidase method with 
diaminobenzidine (Sigma-Aldrich) as a chromogen substrate. Each run included negative controls in which the primary antibody was replaced with non-immune rabbit or mouse serum (Sigma-Aldrich).

The percentage of ductal, cyst, and alveolar epithelial cells that expressed BrdU, PR, and ESR1 was quantified in each tissue section. Two mammary tissue sections per animal and at least 2000 cells per tissue section were analyzed.

\section{Hormone Assay}

E serum levels were measured in blood samples of 15-monthold E-treated rats by radioimmunoassay after ethyl ether (Merck, Buenos Aires, Argentina) extraction, as previously described by Vigezzi et al. [39].

\section{Statistical Analysis}

All data are expressed as the mean \pm SE of 10 animals per group (1 female/litter). The measured variables did not follow a normal distribution (Shapiro-Wilk normality test, SPSSPASW Statistics v. 18); therefore, Mann-Whitney or Kruskal-Wallis analysis was performed to obtain the overall significance, and Dunn's post hoc test after Kruskal-Wallis was used to compare each experimental group with the control group. In all cases, values with $p<0.05$ were considered significant.

\section{Results}

As previously demonstrated [34, 36-39], the treatment with DES $(5 \mu \mathrm{g} / \mathrm{kg} /$ day) or BPA $(0.5$ or $50 \mu \mathrm{g} / \mathrm{kg} /$ day $)$ from GD9 until weaning, administered in the drinking water, produced no signs of embryo toxicity, abnormal maternal or nursing behaviors, or changes in the body weight gain or water consumption of the F0 dams. The length of gestation was unaltered, and no gross malformations were observed in the F1 pups at delivery or weaning. The litter sex ratio showed no alterations and was within the normal range $(50 \%$ females and $50 \%$ males).

V-OVX-V rats showed E levels below the detection limit of the assay. No significant differences in E serum levels (pg/ml) were observed in 15-month-old E-treated rats [V-OVX-E: $19.2 \pm 4.3$; DES-OVX-E: $11.5 \pm 7.5$; BPA0.5-OVX-E: $19.3 \pm 9.8$; and BPA50-OVX-E: $11.0 \pm 7.0]$.

\section{ERT and Mammary Gland of Middle-Aged Rats}

The mammary gland of virgin females is dominated by scattered branched tubular ducts [43], and this feature was observed in intact 15-month-old females (Fig. 2a, d). Due to ovariectomy, ductal and alveolar epithelium atrophy was seen in the mammary gland of V-OVX-V rats (Fig. 2b, e). The ERT (V-OVX-E group) induced ductal and alveolar dilation, areas with secretion, vacuolation, and intraepithelial fat globules mimicking secretory activity as well as lobular hyperplasia (Fig. 2c, f-h). Moreover, $4.2 \pm 0.9 \%$ of the ducts present in V-OVX-E rats were classified as cysts (Fig. 2i), whereas this benign lesion was absent in intact middle-aged and V-OVX-V animals.

Taking into consideration the development of the mammary gland induced by ERT, the proliferation index (quantified as the percentage of cells that incorporated BrdU in the $2 \mathrm{~h}$ previous to sacrifice) and the percentage of epithelial cells expressing ESR1 and PR were analyzed in the different mammary gland structures present in V-OVX-V and V-OVX-E animals; representative images are shown in Fig. 3. The ducts of V-OVX-E animals had a higher proliferation index than those of V-OVX-V rats (Table $1, p<0.05$, Mann-Whitney test). However, the ductal expression of ESR1 was lower in $\mathrm{V}-\mathrm{OVX}$-E animals than in $\mathrm{V}-\mathrm{OVX}-\mathrm{V}$ rats (Table $1, p<0.05$, Mann-Whitney test). In V-OVX-V animals, PR expression was mainly cytoplasmic (Fig. 3). After the treatment with E, PR was translocated to the nucleus of the ductal epithelial cells (Fig. 3, Table 1). Both cysts and alveolar cells proliferated and expressed ESR1 and PR (Fig. 3, Table 1).

\section{Perinatal Exposure to DES and ERT}

As expected, ERT in OVX rats induced a pregnancy/early lactation-like state in the mammary gland with development of the lobuloalveolar structure as well as secretory activity of the epithelial cells and ductal cysts (Fig. 2). In DES-OVX-E animals, the degree of mammary development was higher than in V-OVX-E rats (Fig. 4a-d). Not only the ductal cysts were significantly increased (Fig. 5a), but also in two out of ten animals, neoplastic transformation of the mammary gland structures in the form of fibroadenoma (Fig. 6a) and ductal carcinoma in situ (DCIS) (Fig. 6b) was observed. However, there were no differences between both groups in either percentage of ductal hyperplasia (Fig. 5b) or atypical lobular hyperplasia (Fig. 5c).

Considering the different structures in the mammary gland after ERT, the proliferation index and ESR1 and PR expression were quantified separately in each one. In general, in VOVX-E rats, the proliferation index of the ductal epithelial cells was lower than that of the cystic and alveolar cells (Table $1, p<0.05$, Kruskal-Wallis followed by Dunn's posttest). In addition, cystic cells had lower expression of ESR1 and PR than the epithelial cells of the ducts and alveoli (Table $1, p<0.05$, Kruskal-Wallis followed by Dunn's posttest). No differences in proliferation or ESR1 and PR expression were observed between V-OVX-E and DES-OVX-E animals (Table 1). 

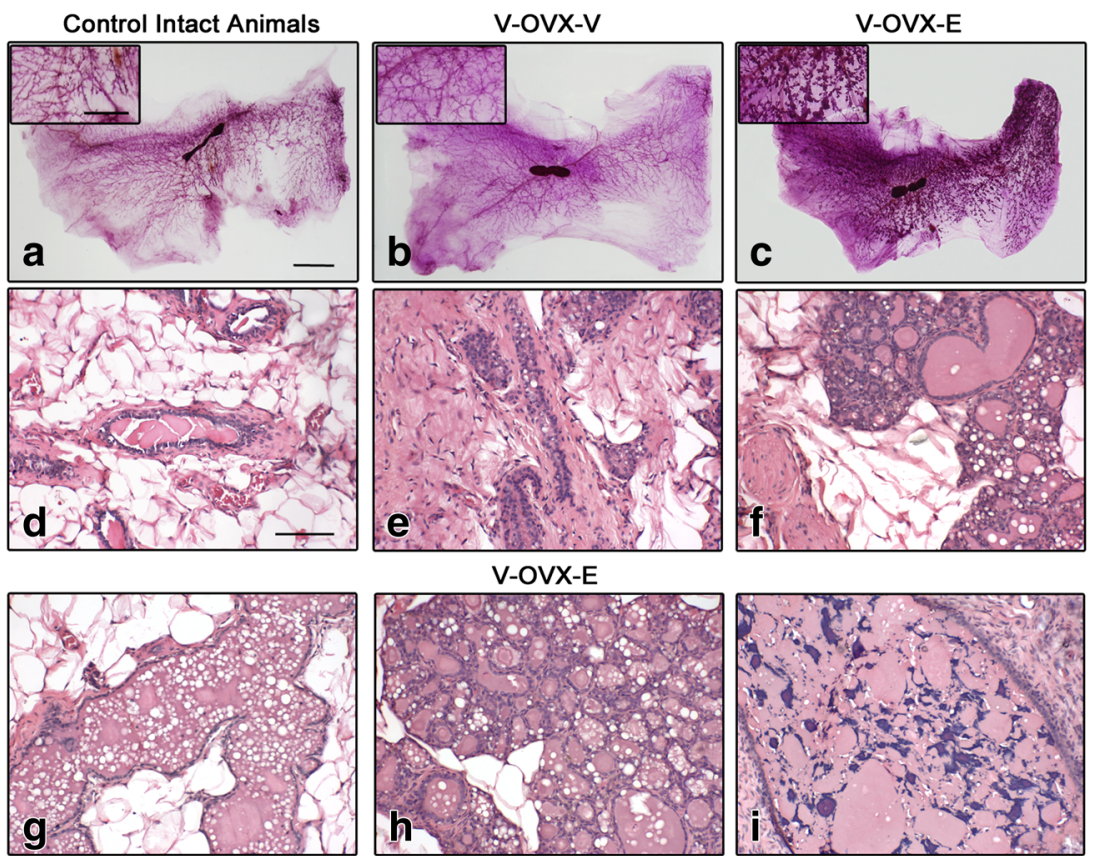

Fig. 2 ERT in middle-aged OVX rats. Representative images of whole mounts $(\mathbf{a}-\mathbf{c})$ and $\mathrm{H} \& \mathrm{E}$-stained sections $(\mathbf{d}-\mathbf{i})$ of intact control animals $(\mathbf{a}$ d), V-OVX-V (b, e), and V-OVX-E rats $(\mathbf{c}, \mathbf{f}-\mathbf{i})$. The higher lobular development in estrogen-treated rats (c) compared with those given vehicle (b) is noteworthy. In V-OVX-V animals, atrophy of the mammary gland after OVX is characterized by scarce number of ducts and lobuloalveolar structures and, a relative increase in collagen amount (e) compared with intact animals (d). E treatment induced alveolar and ductal dilation (f, $\mathbf{g}$ ), areas with secretion, vacuolation, and intraepithelial fat globules mimicking secretory activity, as well as lobular hyperplasia (h) and cysts containing small corpora amylacea (i). In the insets, an area between the nipple and the lymph node in each whole mount is magnified. The bar represents the magnification in each set of images: $10 \mathrm{~mm}$ for $\mathbf{a}-\mathbf{c} ; 5 \mathrm{~mm}$ for whole mount insets, and $100 \mu \mathrm{m}$ for $\mathbf{d}-\mathbf{i}$
Fig. 3 Proliferation and steroid hormone receptor expression in V-OVX-V and V-OVX-E rats. All three markers were analyzed in the epithelial cells of ducts, cysts, and alveoli when the structure was present in mammary gland samples. BrdU and ESR1 expression was identified in the nuclei of epithelial cells, regardless of the mammary structure and experimental group. PR expression in V-OVX-V animals was mainly observed in the cytoplasm whereas that in V-OVX-E rats was mainly observed in the nucleus. Positive cells are indicated by the arrows; note the lower ESR1 and PR expression in cysts compared with ducts and alveoli. All images have the same magnification, bar: $100 \mu \mathrm{m}$

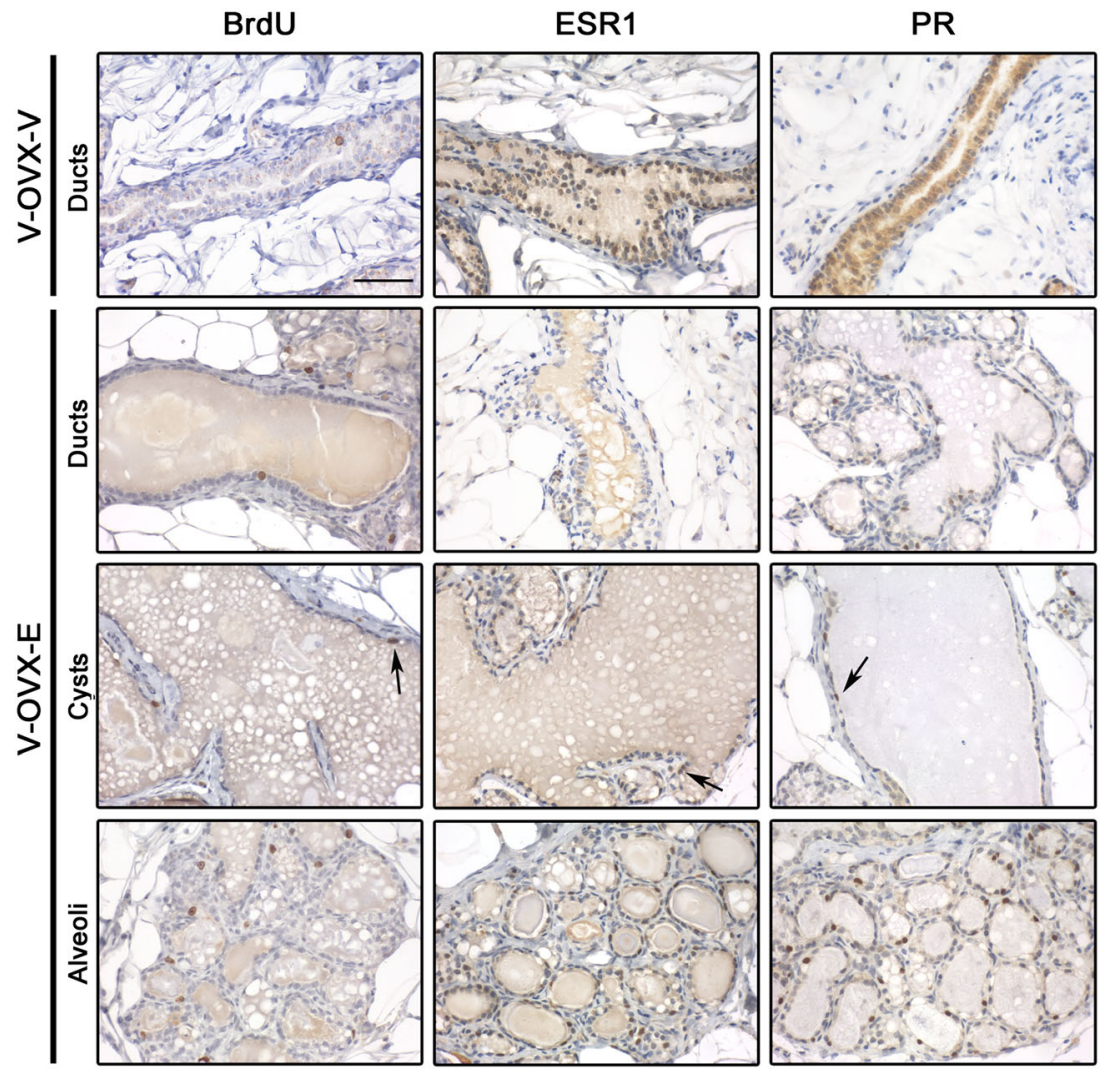


Table 1 Proliferation, ESR1, and PR expression in all experimental groups

\begin{tabular}{|c|c|c|c|c|c|c|}
\hline & & V-OVX-V & V-OVX-E & DES-OVX-E & BPA0.5-OVX-E & BPA50-OVX-E \\
\hline \multirow[t]{3}{*}{ Proliferation $(\%)$} & Ducts & $0.4 \pm 0.2^{\mathrm{a}}$ & $1.6 \pm 0.2^{\mathrm{b}}$ & $1.4 \pm 0.1^{\mathrm{b}}$ & $1.2 \pm 0.4$ & $1.3 \pm 0.2^{\mathrm{b}}$ \\
\hline & Cysts & NP & $3.6 \pm 0.4$ & $3.4 \pm 0.3$ & $2.6 \pm 0.7$ & $3.1 \pm 0.6$ \\
\hline & Alveoli & $\mathrm{NP}$ & $3.5 \pm 0.4$ & $3.5 \pm 0.4$ & $2.8 \pm 0.4$ & $3.5 \pm 0.3$ \\
\hline \multirow[t]{3}{*}{ ESR1 (\%) } & Ducts & $22.0 \pm 2.9^{\mathrm{c}}$ & $8.9 \pm 0.7$ & $9.9 \pm 1.1$ & $5.6 \pm 0.7^{\mathrm{d}}$ & $9.6 \pm 1.0$ \\
\hline & Cysts & $\mathrm{NP}$ & $3.1 \pm 0.5^{\mathrm{e}}$ & $2.4 \pm 0.5^{\mathrm{e}}$ & $3.2 \pm 1.1$ & $4.1 \pm 0.9^{\mathrm{e}}$ \\
\hline & Alveoli & NP & $11.1 \pm 0.6$ & $9.9 \pm 0.8$ & $10.9 \pm 1.0$ & $9.5 \pm 0.9$ \\
\hline \multirow[t]{3}{*}{ PR (\%) } & Ducts & Cytoplasm & $10.9 \pm 1.0$ & $12.4 \pm 1.0$ & $10.4 \pm 1.2$ & $11.4 \pm 1.4$ \\
\hline & Cysts & $\mathrm{NP}$ & $3.1 \pm 0.6^{\mathrm{e}}$ & $4.1 \pm 1.0^{\mathrm{e}}$ & $4.7 \pm 1.4$ & $6.0 \pm 1.6$ \\
\hline & Alveoli & NP & $11.1 \pm 0.5$ & $11.4 \pm 0.6$ & $12.7 \pm 1.2$ & $10.1 \pm 1.0$ \\
\hline
\end{tabular}

Values are expressed as mean $\pm \mathrm{SE}$ of 10 animals/group

$N P$ histological structure not present in V-OVX-V animals, Cytoplasm PR expression was not quantified in V-OVX-V due to its cytoplasmic expression ${ }^{a}$ V-OVX-V $<$ V-OVX-E, $p<0.05$ Mann-Whitney test

${ }^{\mathrm{b}}$ The proliferation of ducts is lower than the proliferation of cysts and alveoli $(p<0.05$, Kruskal-Wallis followed by Dunn's post-test)

${ }^{\mathrm{c}} \mathrm{V}-\mathrm{OVX}-\mathrm{V}>\mathrm{V}$-OVX-E, $p<0.05$ Mann-Whitney test

${ }^{\mathrm{d}}$ BPA0.5-OVX-E $<$ V-OVX-E, $p<0.05$ Kruskal-Wallis followed by Dunn's post-test

${ }^{\mathrm{e}}$ ESR1 and PR expression in cysts is lower than in ducts and alveoli $(p<0.05$, Kruskal-Wallis followed by Dunn's post-test $)$

\section{Perinatal Exposure to BPA and ERT}

Representative images of whole mounts and histological sections of the BPA groups are shown in Fig. 4e-h. As stated previously, ERT induced the development of cysts in the mammary gland of OVX animals. Unlike DES, perinatal exposure to BPA did not modify the percentage of ductal cysts after ERT (Fig. 5a). Another difference with DES-OVX-E animals was that BPA0.5-OVX-E induced the development of both mild ductal and atypical lobular hyperplasia (Figs. 5b, c and 6c, d).

In BPA0.5-OVX-E animals, the proliferation index of the epithelial cells of cysts was similar to that of the ductal and alveolar cells, whereas ESR1 expression was higher in alveolar cells than in the epithelial cells of ducts and cysts (Table 1). However, the ductal cells of BPA0.5-OVX-E animals had lower expression of ESR1 than V-OVX-E (Table 1, $p<0.05$, Kruskal-Wallis followed by Dunn's post-test). Regarding PR, alveolar cells had higher expression than the epithelial cells of cysts, and no differences were observed between V-OVX-E and BPA0.5-OVX-E groups. Also, no differences in proliferation, ESR1, and PR expression were observed between BPA50-OVX-E and V-OVX-E rats (Table 1).

\section{Discussion}

The mammary gland is one of the main targets for estrogen action, and there are many evidences about the adverse effects of DES $[20,22,23,44]$ and BPA on this organ (reviewed in [1, 2]). In the present study, we demonstrated that ERT in OVX middle-aged rats induced hyperplasia of the mammary gland and the formation of benign lesions such as cysts. Moreover, perinatal exposure to DES or low doses of BPA can reprogram mammary gland growth and increase its susceptibility to develop further hyperplastic lesions when confronted with ERT later in life.

The results of the Women's Health Initiative (WHI) showed that EPRT significantly increases breast cancer incidence [45] whereas ERT does not affect its incidence [46]. In our experiment, ERT in OVX middle-aged rats induced a proliferative state in the mammary gland but not carcinoma. In OVX animals, ERT caused the appearance of lobuloalveolar hyperplasia and histological features resembling a secretory-like state of the gland such as alveolar dilation and vacuolation of luminal cells. In addition, dilation of the ducts and development of cysts were observed in $\mathrm{V}$ OVX-E animals. In a mouse menopausal experimental model, a single E injection 5 weeks post-ovariectomy produced enlarged mammary duct ends with multiple layers of epithelial cells, but no lobular development [26]. The difference with our results could be due to the cumulative exposure to E (internal exposure and length of dosing) in middle-aged rats. In this regard, Raafat et al. [47] observed maximal side branching after 14 days of ERT or EPRT in OVX mice. In addition, Hofseth et al. [48] observed that women receiving ERT showed significantly greater epithelial density than women not receiving ERT. In our study, the hyperplastic state of the mammary gland after ERT was correlated with an increase in the proliferation index of the epithelial cells. Similar results have been found in mouse menopausal experimental models [26, 47, 49] and in humans with significantly higher epithelial proliferation in the terminal ductal lobular unit of the breast [48]. 
Fig. 4 ERT in rats perinatally exposed to DES and BPA.

Representative images of whole mounts (a, c, e, g) and H\&Estained sections $(\mathbf{b}, \mathbf{d}, \mathbf{f}, \mathbf{h})$ in $\mathrm{V}$ OVX-E (a, b), DES-OVX-E (c, d), BPA0.5-OVX-E (e, f), and BPA50-OVX-E $(\mathbf{g}, \mathbf{h})$ treated rats. Perinatal exposure to DES prior to ERT induced greater development of the mammary gland and an increased percentage of ductal cysts compared with non-perinatally exposed rats. In BPA-exposed animals, presence of secretion, dilation of ducts and alveoli, and lobular hyperplasia are observed. In the insets, an area between the nipple and the lymph node in each whole mount is magnified.

Dilated ducts (\#), alveolar cells with lipid droplets (arrow), and cysts $(*)$ are indicated in the images. The bar represents the magnification in each set of images: $10 \mathrm{~mm}$ for $\mathbf{a}, \mathbf{c}, \mathbf{e}$, and $\mathbf{g}$; $5 \mathrm{~mm}$ for whole mount insets; and $100 \mu \mathrm{m}$ for $\mathbf{b}, \mathbf{d}, \mathbf{f}$, and $\mathbf{h}$
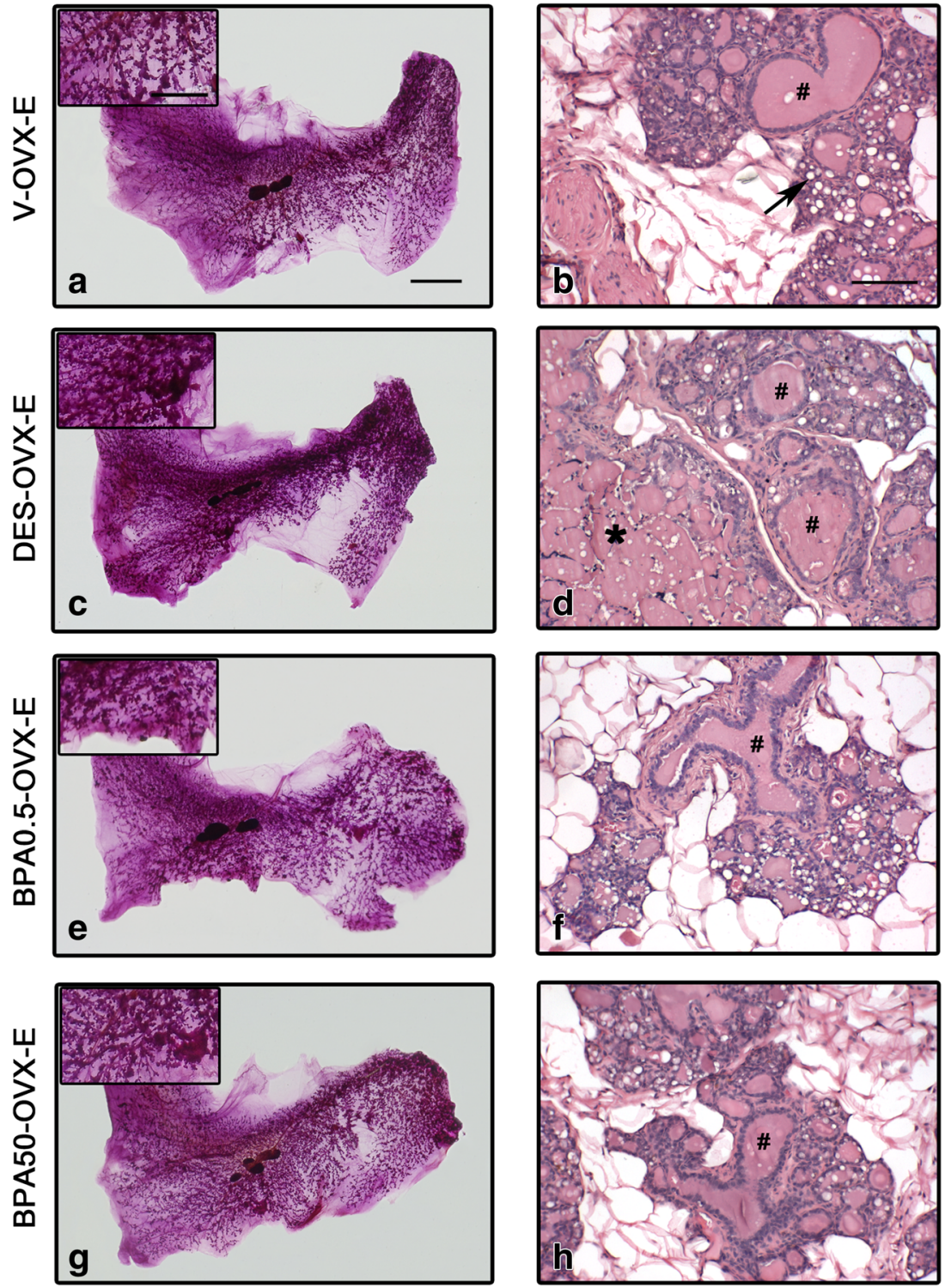

In the mammary gland, estrogen and progesterone mediate their proliferative effects through paracrine signaling [50,51], and in adult animals can modulate the proliferation of mammary gland stem cells (MaSCs) [52, 53]. It is well established that estrogen can exert its effects by binding to specific receptors, and thereby modifying the expression of target genes such as PR [54]. In middle-aged rats, ovariectomy atrophied the gland and fewer ductal structures remained and, unlike women where increasing age is associated with an increase in fat in the breast [55], a denser stroma was observed in these animals. In addition, V-OVX-V rats expressed ESR1, and ERT downregulated its expression in ductal cells. Similar results have been observed in mouse mammary gland [26] and rat uterus [56, 57]. Also, in V-OVX-V animals, PR expression was cytoplasmic. After 3 months of ERT, PR was localized in the nucleus, and a combined ESR1-PR-mediated action in the mammary gland was observed considering the lobuloalveolar development and hyperplasia found in these animals. PR expression in the mammary gland depends on estrogen stimulation. This has been shown in pubertal animals, where the increase in estrogen levels induces the expression of PR in epithelial cells [58], and in 5-week-old OVX mice, where at least 7 days of daily exposure to $\mathrm{E}$ were necessary to induce PR expression above that of control animals [47]. In the present study, due to the ovariectomy, we can assume that the majority of the cytoplasmic PR in V-OVX-V animals is the inactive form of the receptor. Steroid-receptor nuclear import/ export could be disrupted by any experimental manipulation that alters the dynamic exchange of molecular chaperones with receptors [59], and, in V-OVX-V animals, it seems to be favoring nuclear export. ERT, on the other hand, promotes the nuclear localization of PR, and taking into consideration previous work done by Raafat et al. [47], it stimulates PR expression. 

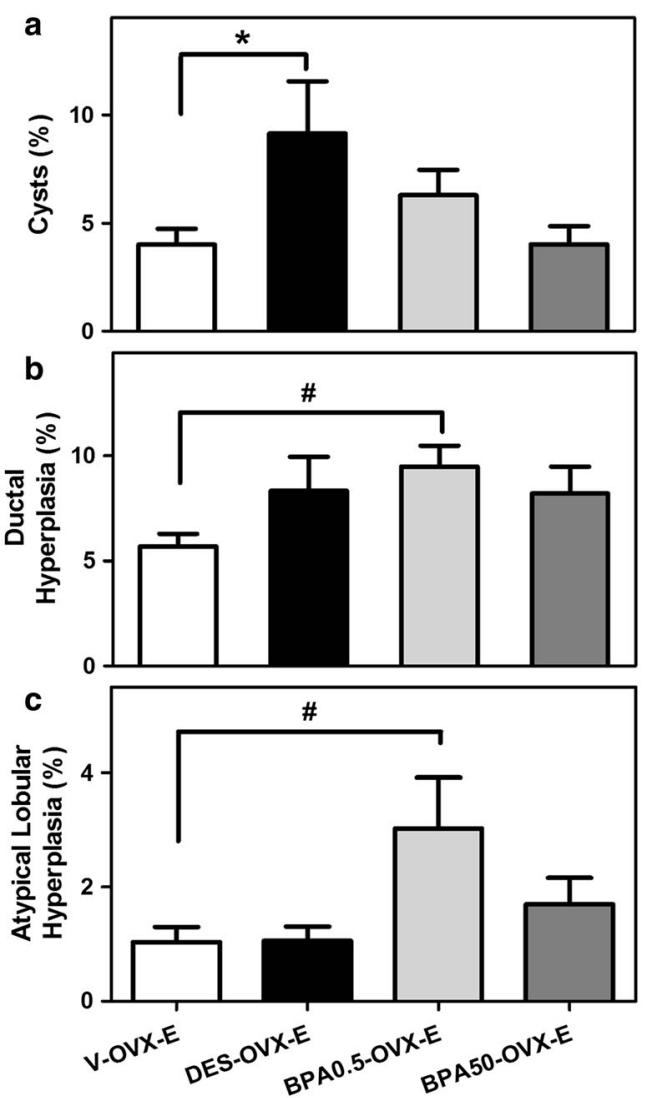

Fig.5 Quantification of cysts and hyperplasia in rats perinatally exposed to DES or BPA after ERT. a Percentage of ductal cysts, b ductal hyperplasia, and $\mathbf{c}$ atypical lobular hyperplasia present in the mammary on PND460. The bars represent the mean value \pm SE of 10 animals/ group. * DES-OVX-V $>$ V-OVX-E, $p<0.05$ Mann-Whitney test. \# BPA0.5-OVX-E $>$ V-OVX-E, $p<0.05$ Kruskal-Wallis followed by Dunn's post-test
Exposure to EDCs starts in utero and never ceases throughout life since these chemicals are present in a large variety of daily products [60]. The general population, including pregnant women, can be exposed to BPA in their daily life through food and drinking water, and non-dietary sources, such as toys and cosmetics [60]. In many countries [61], including Argentina (http://www.anmat.gov.ar/boletin anmat/BO/Disposicion_1207-2012.pdf), the use of polycarbonate in baby bottles has been banned. However, infant food formulations (due to migration of BPA from the packaging material) and breast milk are still important BPA sources of concern [61]. Perturbations in the fetal environment can predispose individuals to disease that will only manifest in adulthood [10]. In this regard, fetal and neonatal exposures to EDCs can cause persistent alterations in the mammary glands long after the exposure has ended [10]. In the case of BPA and DES, the increased susceptibility to develop mammary lesions may have its origin in the altered mammary morphogenesis that occurs during fetal and neonatal exposure [10,20]. Experimental data support the extrapolation that exposure to xenoestrogens during organogenesis in humans contributes to the increase in the incidence of breast cancer observed over recent decades [10]. Moreover, given the long-lived nature of MaSCs, genetic or epigenetic modifications induced by BPA or DES exposure in the fetal and neonatal stage could change the way in which these cells respond to ERT stimulation later in life.

In mice, Hovey et al. [23] showed that a single high dose of DES $36 \mathrm{~h}$ after delivery results in mammary ducts that display extensive dilation 12 weeks after DES injection and that DESexposed animals after ERT present higher level of ductal dilation. Our results show that the association between perinatal exposure to DES and ERT later in life results in a higher
Fig. 6 Mammary gland lesions in perinatally exposed rats after ERT. Representative H\&E images of DES-OVX-E $(\mathbf{a}, \mathbf{b})$ and BPA0.5-OVX-E (c, d) rats. a Fibroadenoma-like lesion, characterized by a secretory-like proliferated glandular epithelium surrounded by layers of proliferated fibrous tissue. $\mathbf{b}$ Incipient DCIS with eosinophilic infiltration. c Hyperplastic duct with three or more layers of epithelial cells. d Lobule with atypical alveoli, characterized by focal, irregular proliferation of the epithelial cells that formed arches or nests extending into the lumen. All images have the same magnification, bar: $100 \mu \mathrm{m}$
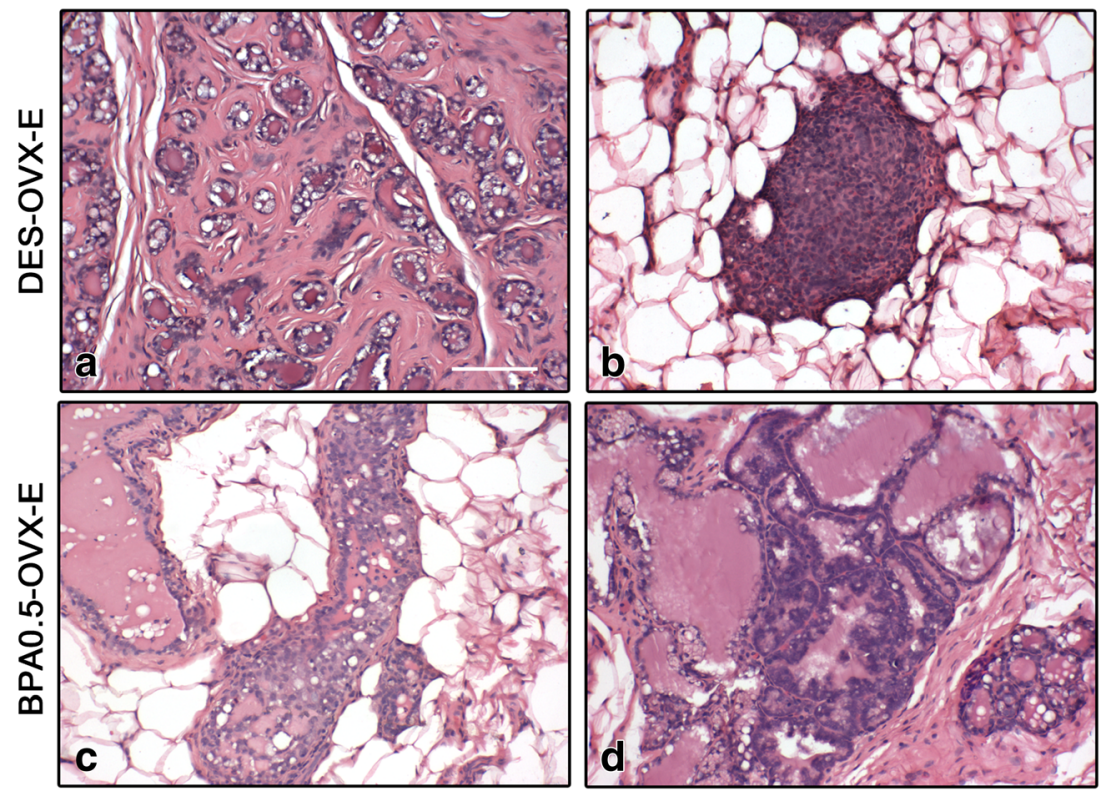
proliferative state of the mammary gland than that found in VOVX-E animals. Besides the lobular hyperplasia and ductal dilation observed in V-OVX-E rats, the incidence of cysts was increased in DES-OVX-E animals. Furthermore, the perinatal dose of DES used $(5 \mu \mathrm{g} / \mathrm{kg} /$ day) was enough to promote the development of fibroadenoma and DCIS in DES-OVX-E rats. These morphological changes cannot be explained by differences in proliferation or ESR 1 and PR expression, at least at the time of analysis. Regarding BPA, in utero exposure to this compound induces the presence of hyperplastic ducts and increases the susceptibility to develop mammary tumors later in life [reviewed in: 2, 13, 62-64]. In the present study, BPA0.5OVX-E treatment induced the increase in both ductal and atypical lobular hyperplasia in middle-aged animals. The high presence of atypical hyperplastic lobules could indicate greater risk of developing lobular carcinoma later in life. No differences in PR expression were observed between groups. However, ductal ESR1 expression was lower only in BPA0.5-OVX-E animals than in the V-OVX-E group. In an experiment similar to that reported here, the uterus of perinatally exposed middle-aged rats presented lower expression of PR in both BPA0.5- and BPA50-OVX-E animals whereas ESR1 expression was lower only in BPA50-OVX-E rats [39]. On the other hand, in postpubertal rats, in utero exposure to BPA $(250 \mu \mathrm{g} / \mathrm{kg} /$ day $)$ increases ESR1 expression in the mammary gland but induces no differences in PR expression [62]. In addition, exposure to BPA ( $50 \mu \mathrm{g} / \mathrm{kg} / \mathrm{day})$ in the first week of age affects the uterine responsiveness to steroid hormones in adulthood, possibly disrupting the transcription machinery assembly of PR- and ESR1-dependent genes [65]. The higher incidence of cysts and the development of benign neoplasms in DES-OVX-E rats as well as the higher percentage of ductal and atypical lobular hyperplasia in BPA0.5OVX-E animals may be a consequence of the dysregulation of endocrine-signaling pathways. Also, perinatal exposure to DES and BPA could induce mutations or epigenetics modifications in the genome that are manifested when the animal is exposed to ERT, resulting in a higher number of mammary gland lesions. In this regard, it has been shown that in utero exposure to DES and BPA increases the expression of histone methyltransferase Enhancer of Zeste Homolog 2 (EZH2) in the mammary gland $[66,67]$. This increase in EZH2 is also observed in the mammary gland of lactating dams that were exposed to BPA $(0.5$ and $50 \mu \mathrm{g} / \mathrm{kg} /$ day $)$ in utero and during lactation [68]. BPA and DES are also able to alter the histone methylation/acetylation status of the breast cancer-associated HOTAIR gene (HOX transcript antisense RNA) [69]. Also, it has been shown that in utero DES exposure alters the methylation patterns of several genes, including Hox genes, c-fox, and Nsbp1, in estrogen target tissues [20], and that in utero exposure to BPA $(250 \mu \mathrm{g} / \mathrm{kg} /$ day $)$ induces epigenome-wide alterations in DNA methylation in mammary tissue of exposed 21-day-old rats, although most transcriptional changes do not occur until PND50 [70]. Further studies are required to determine whether the epigenetic changes prompted by the perinatal exposure to DES and BPA could explain the development of mammary lesions in the experimental groups.

In conclusion, our results add another layer to the complexity of ERT. In individuals that a priori do not have cancerassociated factors and could therefore benefit from shortterm ERT, unknown in utero and/or lactational exposure to EDCs could predispose them to neoplastic transformation of the breast. This new evidence needs to be taken into consideration when health professionals are weighing the severity of menopausal symptoms against the risk of breast cancer attributable to the use of ERT.

Acknowledgments We thank Juan Grant and Juan C. Villarreal (UNL) for their technical assistance and animal care.

G.A.A. and L.V. are fellows, and V.L.B., J.G.R., E.H.L., and L.K. are career investigators of CONICET.

Compliance with Ethical Standards All procedures performed in studies involving animals were in accordance with the ethical standards of the Ethical Committee of the Facultad de Bioquímica y Ciencias Biológicas, Universidad Nacional del Litoral, Santa Fe, Argentina.

Conflict of Interest The authors declare that they have no conflict of interest.

Financial Support This work was supported by grants from Universidad Nacional del Litoral (CAI+D program \#5120110100023LI), Consejo Nacional de Investigaciones Científicas y Técnicas (PIP\#11220110100494), and Agencia Nacional de Promoción Científica y Tecnológica (ANPCyT, PICT 2014 \#1348), Argentina. These funding sources were not involved in the study design, sample collection, analysis or interpretation of the data, the writing of the report, or the decision to submit the article for publication.

\section{References}

1. Vandenberg LN, Ehrlich S, Belcher SM, Ben-Jonathan N, Dolinoy DC, Hugo ER, Hunt PA, Newbold RR, Rubin BS, Saili KS et al (2013) Low dose effects of bisphenol a. Endocrine Disruptors 1(1): e26490. doi:10.4161/endo.26490

2. Seachrist DD, Bonk KW, Ho SM, Prins GS, Soto AM, Keri RA (2015) A review of the carcinogenic potential of bisphenol a. Reprod Toxicol 59:167-182. doi:10.1016/j.reprotox.2015.09.006

3. Soto AM, Sonnenschein C (2015) Endocrine disruptors: DDT, endocrine disruption and breast cancer. Nature Rev Endocrinology 11(9):507-508. doi:10.1038/nrendo.2015.125

4. Cohn BA, La Merrill M, Krigbaum NY, Yeh G, Park JS, Zimmermann L, Cirillo PM (2015) DDT exposure in utero and breast cancer. J Clin Endocrinol Metab 100(8):2865-2872. doi:10.1210/jc.2015-1841

5. Rudel RA, Fenton SE, Ackerman JM, Euling SY, Makris SL (2011) Environmental exposures and mammary gland development: state of the science, public health implications, and research recommendations. Environ Health Perspect 119(8):1053-1061. doi:10.1289/ehp.1002864 
6. Fenton SE, Reed C, Newbold RR (2012) Perinatal environmental exposures affect mammary development, function, and cancer risk in adulthood. Annu Rev Pharmacol Toxicol 52:455-479. doi:10.1146/annurev-pharmtox-010611-134659

7. Macon MB, Fenton SE (2013) Endocrine disruptors and the breast: early life effects and later life disease. J Mammary Gland Biol Neoplasia 18(1):43-61. doi:10.1007/s10911-013-9275-7

8. Gray JM, Maffini MV (2015) Give prevention a chance: reducing environmental exposures to improve breast health. Breast Diseases: A Year Book Quarterly 26(3):197-202. doi:10.1016/j. breastdis.2015.07.038

9. Vandenberg LN, Maffini MV, Sonnenschein C, Rubin BS, Soto AM (2009) Bisphenol-a and the great divide: a review of controversies in the field of endocrine disruption. Endocr Rev 30(1):7595. doi:10.1210/er.2008-0021

10. Soto AM, Brisken C, Schaeberle C, Sonnenschein C (2013) Does cancer start in the womb? Altered mammary gland development and predisposition to breast cancer due to in utero exposure to endocrine disruptors. J Mammary Gland Biol Neoplasia 18(2): 199-208. doi:10.1007/s10911-013-9293-5

11. Richter CA, Birnbaum LS, Farabollini F, Newbold RR, Rubin BS, Talsness CE, Vandenbergh JG, Walser-Kuntz DR, vom Saal FS (2007) In vivo effects of bisphenol a in laboratory rodent studies. Reprod Toxicol 24(2):199-224. doi:10.1016/j.reprotox.2007.06.004

12. Acevedo N, Davis B, Schaeberle CM, Sonnenschein C, Soto AM (2013) Perinatally administered bisphenol a as a potential mammary gland carcinogen in rats. Environ Health Perspect 121(9):1040 1046. doi:10.1289/ehp.1306734

13. Durando M, Kass L, Piva J, Sonnenschein C, Soto AM, Luque EH, Muñoz-de-Toro MM (2007) Prenatal bisphenol a exposure induces preneoplastic lesions in the mammary gland in Wistar rats. Environ Health Perspect 115(1):80-86. doi:10.1289/ehp.9282

14. Moral R, Wang R, Russo IH, Lamartiniere CA, Pereira J, Russo J (2008) Effect of prenatal exposure to the endocrine disruptor bisphenol a on mammary gland morphology and gene expression signature. J Endocrinol 196(1):101-112. doi:10.1677/JOE-07-0056

15. Muñoz-de-Toro M, Markey CM, Wadia PR, Luque EH, Rubin BS, Sonnenschein C, Soto AM (2005) Perinatal exposure to bisphenola alters peripubertal mammary gland development in mice. Endocrinology 146(9):4138-4147. doi:10.1210/en.2005-0340

16. Paulose T, Speroni L, Sonnenschein C, Soto AM (2015) Estrogens in the wrong place at the wrong time: fetal BPA exposure and mammary cancer. Reprod Toxicol 54:58-65. doi:10.1016/j. reprotox.2014.09.012

17. Rochester JR (2013) Bisphenol a and human health: a review of the literature. Reprod Toxicol 42:132-155. doi:10.1016/j. reprotox.2013.08.008

18. Tharp AP, Maffini MV, Hunt PA, VandeVoort CA, Sonnenschein C, Soto AM (2012) Bisphenol a alters the development of the rhesus monkey mammary gland. Proc Natl Acad Sci U S A 109(21):8190 8195. doi:10.1073/pnas.1120488109

19. Delclos KB, Camacho L, Lewis SM, Vanlandingham MM, Latendresse JR, Olson GR, Davis KJ, Patton RE, Gamboa da Costa G, Woodling KA et al (2014) Toxicity evaluation of bisphenol a administered by gavage to Sprague Dawley rats from gestation day 6 through postnatal day 90. Toxicol Sci 139(1):174197. doi:10.1093/toxsci/kfu022

20. Hilakivi-Clarke L (2014) Maternal exposure to diethylstilbestrol during pregnancy and increased breast cancer risk in daughters. Breast Cancer Res 16(2):208. doi:10.1186/bcr3649

21. Swan SH (2000) Intrauterine exposure to diethylstilbestrol: long-term effects in humans. APMIS 108(12):793-804. doi:10.1111/j.1600-0463.2000.tb00001.x

22. Palmer JR, Wise LA, Hatch EE, Troisi R, Titus-Ernstoff L, Strohsnitter W, Kaufman R, Herbst AL, Noller KL, Hyer M et al (2006) Prenatal diethylstilbestrol exposure and risk of breast cancer. Cancer Epidemiol Biomark Prev 15(8):1509-1514. doi:10.1158/1055-9965.EPI-06-0109

23. Hovey RC, Asai-Sato M, Warri A, Terry-Koroma B, Colyn N, Ginsburg E, Vonderhaar BK (2005) Effects of neonatal exposure to diethylstilbestrol, tamoxifen, and toremifene on the BALB/c mouse mammary gland. Biol Reprod 72(2):423-435. doi:10.1095/biolreprod.104.029769

24. Sassarini J, Lumsden MA (2015) Oestrogen replacement in postmenopausal women. Age Ageing 44(4):551-558. doi:10.1093/ageing/afv069

25. MacMahon B, Cole P, Brown J (1973) Etiology of human breast cancer: a review. J Natl Cancer Inst 50(1):21-42. doi:10.1093/jnci/50.1.21

26. Raafat AM, Hofseth LJ, Li S, Bennett JM, Haslam SZ (1999) A mouse model to study the effects of hormone replacement therapy on normal mammary gland during menopause: enhanced proliferative response to estrogen in late postmenopausal mice. Endocrinology 140(6):2570-2580. doi:10.1210/endo.140.6.6634

27. Haslam SZ, Osuch JR, Raafat AM, Hofseth LJ (2002) Postmenopausal hormone replacement therapy: effects on normal mammary gland in humans and in a mouse postmenopausal model. J Mammary Gland Biol Neoplasia 7(1):93-105. doi:10.1023/A:1015726608146

28. Calle EE, Heath CW Jr, Coates RJ, Liff JM, Franceschi S, Talamini R, Chantarakul N, Koetsawang S, Dd R, Ae M et al (1997) Breast cancer and hormone replacement therapy: collaborative reanalysis of data from 51 epidemiological studies of 52,705 women with breast cancer and 108,411 women without breast cancer. Collaborative group on hormonal factors in breast cancer. Lancet 350(9084):1047-1059. doi:10.1016/S0140-6736(97)08233-0

29. Chlebowski RT, Anderson GL (2015) Menopausal hormone therapy and breast cancer mortality: clinical implications. Ther Adv Drug Saf 6(2):45-56. doi:10.1177/2042098614568300

30. Banks E (2015) An evidence-based future for menopausal hormone therapy. Women's Health (Lond Engl) 11(6):785-788. doi:10.2217/whe.15.37

31. Warren MP, Shu AR, Dominguez JE (2000) Menopause and Hormone Replacement, In: L J De Groot, P Beck-Peccoz, G Chrousos, K Dungan, A Grossman, JM Hershman, C Koch, R McLachlan, M New, R Rebar, F Singer, A Vinik, MO Weickert (Eds.) Endotext, South Dartmouth (MA)

32. Gupta PB, Proia D, Cingoz O, Weremowicz J, Naber SP, Weinberg RA, Kuperwasser C (2007) Systemic stromal effects of estrogen promote the growth of estrogen receptor-negative cancers. Cancer Res 67(5):2062-2071. doi:10.1158/0008-5472.CAN-06-3895

33. McConnell JC, O'Connell OV, Brennan K, Weiping L, Howe M, Joseph L, Knight D, O'Cualain R, Lim Y, Leek A et al (2016) Increased peri-ductal collagen micro-organization may contribute to raised mammographic density. Breast Cancer Res 18(1):5. doi:10.1186/s13058-015-0664-2

34. Vigezzi L, Ramos JG, Kass L, Tschopp MV, Muñoz-de-Toro M, Luque EH, Bosquiazzo VL (2016) A deregulated expression of estrogen-target genes is associated with an altered response to estradiol in aged rats perinatally exposed to bisphenol a. Mol Cell Endocrinol 426:33-42. doi:10.1016/j.mce.2016.02.010

35. Andreoli MF, Stoker C, Rossetti MF, Alzamendi A, Castrogiovanni D, Luque EH, Ramos JG (2015) Withdrawal of dietary phytoestrogens in adult male rats affects hypothalamic regulation of food intake, induces obesity and alters glucose metabolism. Mol Cell Endocrinol 401:111-119. doi:10.1016/j.mce.2014.12.002

36. Altamirano GA, Muñoz-de-Toro M, Luque EH, Gomez AL, Delconte MB, Kass L (2015) Milk lipid composition is modified by perinatal exposure to bisphenol a. Mol Cell Endocrinol 411: 258-267. doi:10.1016/j.mce.2015.05.007

37. Kass L, Altamirano GA, Bosquiazzo VL, Luque EH, Muñoz-deToro M (2012) Perinatal exposure to xenoestrogens impairs 
mammary gland differentiation and modifies milk composition in Wistar rats. Reprod Toxicol 33(3):390-400. doi:10.1016/j. reprotox.2012.02.002

38. Bosquiazzo VL, Vigezzi L, Muñoz-de-Toro M, Luque EH (2013) Perinatal exposure to diethylstilbestrol alters the functional differentiation of the adult rat uterus. J Steroid Biochem Mol Biol 138:19. doi:10.1016/j.jsbmb.2013.02.011

39. Vigezzi L, Bosquiazzo VL, Kass L, Ramos JG, Muñoz-de-Toro M, Luque EH (2015) Developmental exposure to bisphenol a alters the differentiation and functional response of the adult rat uterus to estrogen treatment. Reprod Toxicol 52:83-92. doi:10.1016/j. reprotox.2015.01.011

40. Kass L, Varayoud J, Ortega H, Muñoz-de-Toro M, Luque EH (2000) Detection of bromodeoxyuridine in formalin-fixed tissue. DNA denaturation following microwave or enzymatic digestion pretreatment is required. Eur J Histochem 44(2):185-191

41. Rudmann D, Cardiff R, Chouinard L, Goodman D, Kuttler K, Marxfeld H, Molinolo A, Treumann S, Yoshizawa K (2012) Proliferative and nonproliferative lesions of the rat and mouse mammary, Zymbal's, preputial, and clitoral glands. Toxicol Pathol 40(6 Suppl):7S-39S. doi:10.1177/0192623312454242

42. Kass L, Durando M, Altamirano GA, Manfroni-Ghibaudo GE, Luque EH, Muñoz-de-Toro M (2015) Prenatal bisphenol a exposure delays the development of the male rat mammary gland. Reprod Toxicol 54:37-46. doi:10.1016/j.reprotox.2014.02.001

43. Lucas JN, Rudmann DG, Credille KM, Irizarry AR, Peter A, Snyder PW (2007) The rat mammary gland: morphologic changes as an indicator of systemic hormonal perturbations induced by xenobiotics. Toxicol Pathol 35(2):199-207. doi:10.1080/01926230601156260

44. Rothschild TC, Boylan ES, Calhoon RE, Vonderhaar BK (1987) Transplacental effects of diethylstilbestrol on mammary development and tumorigenesis in female ACI rats. Cancer Res 47(16): $4508-4516$

45. Chlebowski RT, Hendrix SL, Langer RD, Stefanick ML, Gass M, Lane D, Rodabough RJ, Gilligan MA, Cyr MG, Thomson CA et al (2003) Influence of estrogen plus progestin on breast cancer and mammography in healthy postmenopausal women: the Women's Health Initiative randomized trial. JAMA 289(24):3243-3253. doi:10.1001/jama.289.24.3243

46. Stefanick ML, Anderson GL, Margolis KL, Hendrix SL, Rodabough RJ, Paskett ED, Lane DS, Hubbell FA, Assaf AR, Sarto GE et al (2006) Effects of conjugated equine estrogens on breast cancer and mammography screening in postmenopausal women with hysterectomy. JAMA 295(14):1647-1657. doi:10.1001/jama.295.14.1647

47. Raafat AM, Hofseth LJ, Haslam SZ (2001) Proliferative effects of combination estrogen and progesterone replacement therapy on the normal postmenopausal mammary gland in a murine model. Am J Obstet Gynecol 184(3):340-349. doi:10.1067/mob.2001.110447

48. Hofseth LJ, Raafat AM, Osuch JR, Pathak DR, Slomski CA, Haslam SZ (1999) Hormone replacement therapy with estrogen or estrogen plus medroxyprogesterone acetate is associated with increased epithelial proliferation in the normal postmenopausal breast. J Clin Endocrinol Metab 84(12):4559-4565. doi:10.1210/jcem.84.12.6194

49. Raafat AM, Li S, Bennett JM, Hofseth LJ, Haslam SZ (2001) Estrogen and estrogen plus progestin act directly on the mammary gland to increase proliferation in a postmenopausal mouse model. J Cell Physiol 187(1):81-89. doi:10.1002/1097-4652 (2001)9999:9999<::AID-JCP1056>3.0.CO;2-0

50. Mallepell S, Krust A, Chambon P, Brisken C (2006) Paracrine signaling through the epithelial estrogen receptor alpha is required for proliferation and morphogenesis in the mammary gland. Proc Natl Acad Sci U S A 103(7):2196-2201. doi:10.1073/pnas.0510974103
51. Brisken C, Park S, Vass T, Lydon JP, O’Malley BW, Weinberg RA (1998) A paracrine role for the epithelial progesterone receptor in mammary gland development. Proc Natl Acad Sci U S A 95(9): 5076-5081

52. Asselin-Labat ML, Vaillant F, Sheridan JM, Pal B, Wu D, Simpson ER, Yasuda H, Smyth GK, Martin TJ, Lindeman GJ et al (2010) Control of mammary stem cell function by steroid hormone signalling. Nature 465(7299):798-802. doi:10.1038/nature09027

53. Joshi PA, Jackson HW, Beristain AG, Di Grappa MA, Mote PA, Clarke CL, Stingl J, Waterhouse PD, Khokha R (2010) Progesterone induces adult mammary stem cell expansion. Nature 465(7299):803-807. doi:10.1038/nature09091

54. Haslam SZ (1988) Acquisition of estrogen-dependent progesterone receptors by normal mouse mammary gland. Ontogeny of mammary progesterone receptors. J Steroid Biochem 31(1):9-13. doi:10.1016/0022-4731(88)90199-9

55. Ginsburg OM, Martin LJ, Boyd NF (2008) Mammographic density, lobular involution, and risk of breast cancer. Br J Cancer 99(9): 1369-1374. doi:10.1038/sj.bjc.6604635

56. Varayoud J, Monje L, Bernhardt T, Muñoz-de-Toro M, Luque EH, Ramos JG (2008) Endosulfan modulates estrogen-dependent genes like a non-uterotrophic dose of 17beta-estradiol. Reprod Toxicol 26(2):138-145. doi:10.1016/j.reprotox.2008.08.004

57. Varayoud J, Ramos JG, Monje L, Bosquiazzo V, Muñoz-deToro M, Luque EH (2005) The estrogen receptor alpha sigma3 mRNA splicing variant is differentially regulated by estrogen and progesterone in the rat uterus. J Endocrinol 186(1):51-60. doi:10.1677/joe.1.06099

58. Haslam SZ, Shyamala G (1979) Effect of oestradiol on progesterone receptors in normal mammary glands and its relationship with lactation. Biochem J 182(1):127-131. doi:10.1042/bj1820127

59. DeFranco DB (1999) Regulation of steroid receptor subcellular trafficking. Cell Biochem Biophys 30(1):1-24. doi:10.1007/BF02737882

60. Giulivo M, Lopez de Alda M, Capri E, Barcelo D (2016) Human exposure to endocrine disrupting compounds: their role in reproductive systems, metabolic syndrome and breast cancer. A review. Environ Res 151:251-264. doi:10.1016/j.envres.2016.07.011

61. Corrales J, Kristofco LA, Steele WB, Yates BS, Breed CS, Williams ES, Brooks BW (2015) Global assessment of bisphenol a in the environment: review and analysis of its occurrence and bioaccumulation. Dose Response 13(3):1559325815598308. doi:10.1177/1559325815598308

62. Durando M, Kass L, Perdomo V, Bosquiazzo VL, Luque EH, Muñoz-de-Toro M (2011) Prenatal exposure to bisphenol a promotes angiogenesis and alters steroid-mediated responses in the mammary glands of cycling rats. J Steroid Biochem Mol Biol 127(1-2):35-43. doi:10.1016/j.jsbmb.2011.04.001

63. Betancourt AM, Eltoum IA, Desmond RA, Russo J, Lamartiniere CA (2010) In utero exposure to bisphenol a shifts the window of susceptibility for mammary carcinogenesis in the rat. Environ Health Perspect 118(11):1614-1619. doi:10.1289/ehp.1002148

64. Murray TJ, Maffini MV, Ucci AA, Sonnenschein C, Soto AM (2007) Induction of mammary gland ductal hyperplasias and carcinoma in situ following fetal bisphenol a exposure. Reprod Toxicol 23(3):383-390. doi:10.1016/j.reprotox.2006.10.002

65. Varayoud J, Ramos JG, Bosquiazzo VL, Muñoz-de-Toro M, Luque EH (2008) Developmental exposure to bisphenol a impairs the uterine response to ovarian steroids in the adult. Endocrinology 149(11):5848-5860. doi:10.1210/en.2008-0651

66. Doherty LF, Bromer JG, Zhou Y, Aldad TS, Taylor HS (2010) In utero exposure to diethylstilbestrol (DES) or bisphenol-a (BPA) increases EZH2 expression in the mammary gland: an epigenetic mechanism linking endocrine disruptors to breast cancer. Horm Cancer 1(3):146-155. doi:10.1007/s12672-010-0015-9 
67. Bhan A, Hussain I, Ansari KI, Bobzean SA, Perrotti LI, Mandal SS (2014) Histone methyltransferase EZH2 is transcriptionally induced by estradiol as well as estrogenic endocrine disruptors bisphenol-a and diethylstilbestrol. J Mol Biol 426(20):3426-3441. doi:10.1016/j.jmb.2014.07.025

68. Altamirano GA, Ramos JG, Gomez AL, Luque EH, Muñoz-deToro M, Kass L (2017) Perinatal exposure to bisphenol a modifies the transcriptional regulation of the beta-casein gene during secretory activation of the rat mammary gland. Mol Cell Endocrinol 439: 407-418. doi: 10.1016/j.mce.2016.09.032
69. Bhan A, Hussain I, Ansari KI, Bobzean SA, Perrotti LI, Mandal SS (2014) Bisphenol-a and diethylstilbestrol exposure induces the expression of breast cancer associated long noncoding RNA HOTAIR in vitro and in vivo. J Steroid Biochem Mol Biol 141:160-170. doi:10.1016/j.jsbmb.2014.02.002

70. Dhimolea E, Wadia PR, Murray TJ, Settles ML, Treitman JD, Sonnenschein C, Shioda T, Soto AM (2014) Prenatal exposure to BPA alters the epigenome of the rat mammary gland and increases the propensity to neoplastic development. PLoS One 9(7):e99800. doi:10.1371/journal.pone.0099800 